\title{
Promoting pro-environmental behavior in ecotourism destination
}

\begin{abstract}
Promoting pro-environmental behaviors in ecotourism areas is important in the management of conflicts in ecotourism particularly in humanï natural resources conflict as the degradation of the environment in ecotourism areas is strongly affected by visitorsô depreciative behaviors. Therefore, this paper reviews the contributions and potentials of environmental psychology for understanding and promoting pro-environmental behaviors in ecotourism destination comprising ecotourism resources and pro-environmental behaviors, process of promoting pro-environmental behaviors, three selected frameworks such as norm activation model (NAM), value belief norm theory $(\mathrm{VBN})$, and theory of planned behavior (TPB) in analyzing pro-environmental behaviors, factors underlying, and intervention strategies that can be adopted in promoting environmental behaviors. The result shows that promoting proenvironmental behaviors in ecotourism areas is more effective when it is systematically planned. In doing so, one must first determine the depreciative behaviors that needed to be changed. Hence, identification of the factors and barriers underlying depreciative behaviors is crucial in order to plan for the strategies of the intervention objectify at changing that depreciative behaviors toward pro-environmental actions. This paper aimed to enable the development of effective decision makings in handling the conflicts of ecotourism product or resource management.
\end{abstract}

Keyword: Ecotourism; Intervention strategies; Pro-environmental behaviors 